\title{
US FDA Drug Approvals are Persistent and Polycyclic: Insights into Economic Cycles, Innovation Dynamics, and National Policy
}

\author{
Iraj Daizadeh ${ }^{1}$ D
}

Received: 12 November 2020 / Accepted: 17 March 2021 / Published online: 30 March 2021

(c) The Drug Information Association, Inc 2021

\begin{abstract}
It is challenging to elucidate the effects of changes in external influences (such as economic or policy) on the rate of US drug approvals. Here, a novel approach—-termed the Chronological Hurst Exponent (CHE)—is proposed, which hypothesizes that changes in the long-range memory latent within the dynamics of time series data may be temporally associated with changes in such influences. Using the monthly number FDA's Center for Drug Evaluation and Research (CDER) approvals from 1939 to 2019 as the data source, it is demonstrated that the CHE has a distinct S-shaped structure demarcated by an 8-year (1939-1947) Stagnation Period, a 27-year (1947-1974) Emergent Period, and a 45-year (1974-2019) Saturation Period. Further, dominant periodicities (resolved via wavelet analyses) are identified during the most recent 45-year CHE Saturation Period at 17, 8 and 4 years; thus, US drug approvals have been following a Juglar/Kuznet mid-term cycle with Kitchin-like bursts. As discussed, this work suggests that (1) changes in extrinsic factors (e.g., of economic and/or policy origin) during the Emergent Period may have led to persistent growth in US drug approvals enjoyed since 1974, (2) the CHE may be a valued method to explore influences on time series data, and (3) innovation-related economic cycles exist (as viewed via the proxy metric of US drug approvals).
\end{abstract}

Keywords FDA approvals $\cdot$ Drug development $\cdot$ Medical product $\cdot$ Medicines $\cdot$ Economic cycle $\cdot$ Schumpeter

\section{Introduction}

Drug discovery and development (DDD) requires investment to maneuver a single putative medicine from discovery science to market approval for a given condition or disease. The investments cover the costs associated with acquiring both the hardware (e.g., laboratory materials and space) and software [explicit (e.g., patents) and tacit (e.g., know-how) knowledge] as well as executing the various DDD activities [1]. Ultimately, should an investigational candidate survive the attrition process and obtain marketing authorization (also known as marketing approval) by a health authority, a sponsor then enjoys economic rents secured from supplying the approval medicine. On the demand side, the patient receives a trusted medicine associated with a market innovation based on a new chemical and biologic entity, a cost

Iraj Daizadeh

iraj.daizadeh@takeda.com

1 Takeda Pharmaceuticals, 40 Landsdowne St, Cambridge, MA 02139, USA advantage (generic), or a more efficient delivery of drug product [2].

Since the early twentieth century to the present, in terms of drug development, the social, economic, and political environments have evolved dramatically. For example, the growth in the amount of governmental investment in research and development (R\&D) [3], the number of $R \& D$ firms $[4,5]$, the volume of intellectual property (e.g., patents, trademarks, as well as peer-reviewed publications) [5, 6], the number of R\&D policy initiatives (see Table 1 and discussion below), and the rise of the R\&D cluster [7] have seemingly grown synchronistically and exponentially. As a case in point, in the US and across industries, Daizadeh [8, 9] showed a statistical significant intercorrelation in the time course of R\&D investment, the number of patent and trademark applications, peer-reviewed and media publications, and stock price of major indices in the US.

Importantly, the twentieth century also gave rise to the modern regulated DDD industry including the invention of an objective, independent, and external agency [collectively termed the health authority (HA)]. The HA performs a vital function by attesting to a medicine's quality, safety, and 
Table 1 Brief Milestones in FDA Drug Regulation [10, 37]

\begin{tabular}{|c|c|}
\hline Year & US Drug Regulation \\
\hline 1938 & Act and Requirements for Premarket Drug Safety and New Labeling \\
\hline 1941 & The Insulin Amendment \\
\hline 1945 & The Penicillin Amendment \\
\hline 1951 & Durham-Humphrey Amendment \\
\hline 1962 & Kefauver-Harris Drug Amendments \\
\hline 1977 & Introduction of the Bioresearch Monitoring Program \\
\hline 1981 & Revision of the regulations for human subject protections \\
\hline 1982 & Tamper-resistant Packaging Regulations issued \\
\hline 1983 & Orphan Drug Act \\
\hline 1984 & Drug Price Competition and Patent Term Restoration Act (Hatch-Waxman Act) \\
\hline 1987 & Investigational drug regulations \\
\hline 1988 & FDA Act of 1988 and Prescription Drug Marketing Act \\
\hline 1989 & Guidelines on significant use in elderly people \\
\hline 1991 & Accelerated review of drugs for life-threatening diseases; Common Rule adopted across agencies \\
\hline 1992 & $\begin{array}{l}\text { Generic Drug Enforcement Act; co-establishes International Conference on Harmonization (ICH); Pre- } \\
\text { scription Drug User Fee Act (PDUFA I) }\end{array}$ \\
\hline 1993 & $\begin{array}{l}\text { MedWatch launched; revising women of childbearing potential in early phase drug studies policies and } \\
\text { assessments of genders-specific medication responses }\end{array}$ \\
\hline 1994 & Uruguay Round Agreements Act \\
\hline 1995 & Cigarettes as 'drug delivery devices' \\
\hline 1997 & FDA Modernization Act (FDAMA); reauthorization of PDUFA II \\
\hline 1998 & Adverse Event Reporting System (AERS); Demographic Rule; Pediatric Rule \\
\hline 1999 & $\begin{array}{l}\text { ClinicalTrials.gov; guidances for electronic submissions; drug facts; Prescription Drug Broadcasting } \\
\text { Advertising Final Guidance; Managing the Risks from Medical Product use: Risk Management Frame- } \\
\text { work published }\end{array}$ \\
\hline 2000 & Data Quality Act \\
\hline 2002 & $\begin{array}{l}\text { Best Pharmaceuticals for Children Act; Public Health Security and Bioterrorism Preparedness and } \\
\text { Response Act of 2002; Current good manufacturing practice (cGMP) initiative; PDUFA III; outcomes } \\
\text { of pregnancies registries guidance }\end{array}$ \\
\hline 2003 & Medicare Prescription Drug Improvement and Modernization Act; Pediatric Research Equity Act \\
\hline 2004 & $\begin{array}{l}\text { Project BioShield Act of 2004; Anabolic Steroid Control Act of 2004; "Innovation or Stagnation?- } \\
\text { Challenge and Opportunity on the Critical Path to New Medical Products" published; bar code intro- } \\
\text { duced }\end{array}$ \\
\hline 2005 & Drug Safety Board announced; risk management performance goal guidances \\
\hline 2006 & $\begin{array}{l}\text { Requirements on Content and Format of Labeling for Human Prescription Drug and Biological Products } \\
\text { final rule }\end{array}$ \\
\hline 2007 & PDUFA IV; FDA Amendments Act (FDAAA) \\
\hline 2008 & Sentinel Initiative \\
\hline 2009 & FDA Transparency Initiative \\
\hline 2010 & FDA Transparency Results Accountability Credibility Knowledge Sharing (TRACK) \\
\hline 2012 & $\begin{array}{l}\text { PDUFA V; Launch of FDA Adverse Event Reporting System (FAERS); Food and Drug Administration } \\
\text { Safety and Innovation Act (FDASIA); Generic Drug User Fee Amendment }\end{array}$ \\
\hline 2013 & $\begin{array}{l}\text { Drug Quality and Security Act; Mobile Medical Applications; Global Unique Device Identification } \\
\text { Database (GUDID) }\end{array}$ \\
\hline 2016 & 21st Century Cures Act \\
\hline 2017 & $\begin{array}{l}\text { Current Good Manufacturing Practice (cGMP) Requirements for Combination Products; FDA Reau- } \\
\text { thorization Act (FDARA; PDUFA VI) }\end{array}$ \\
\hline
\end{tabular}

https://www.fda.gov/about-fda/virtual-exhibits-fda-history/brief-history-center-drug-evaluation-and-research

efficacy profile and to formally authorize a drug for marketing purposes in a given jurisdiction. Since its original conception, there have been increasing refinement in its scope proportional to changes in the social environment 
through amendments in policy. For example, focusing on the US Food and Drug Administration (FDA), there has been an evolution in the number and variety of policy initiatives focused on providing oversight to the DDD process due exclusively to important social concerns regarding safety and efficacy of certain drugs circulating in inter-jurisdictional commerce [10]. The FDA policy environment has evolved considerably from placing under regulation on specific drugs (e.g., insulin and penicillin) and describing the basic tenets of the safety sciences in its infancy to building a robust infrastructure commencing in the 1960s with the Kefauver-Harris amendments to regular updates in the policy landscape starting in 1977, with the introduction of the Bioresearch Monitoring Program, pushing the frontiers of regulatory science into the twenty-first century (see Table 1).

Concomitantly, economic factors have also greatly influenced the landscape of DDD. Unlike the US (21 CFR 310 et seq.; 21 CFR 601 et seq.), in many jurisdictions (e.g., the European Union), HAs consider cost and/or reimbursement when assessing the merits of granting a marketing application. The ability of sponsors to obtain the economic rents from supplying quality, safe and efficacious HA-authorized drugs is a key driver that has sustained the DDD process. Among other factors, expected revenues from marketing an innovative HA-approved drug product would be proportional to monopolizing power of the intellectual property [1] as well as the amount of labor required to move the drug from concept to delivery, thereby requiring a broad assortment of various investments in terms of tangible and intangible assets. While beyond the scope of this work, cost estimates to secure marketing authorization vary based on the types of challenges experienced in various phases (e.g. target/modality in discovery; the number, length and type of clinical trials in development) [11], with significant savings expected with expediting development [12]. Thus, drug approvals may be thought of an economic outcome within a given jurisdiction, and should behave as such. One such test would be to investigate the presence of cycles in the number of approvals similar to that found in other forms of economic output.

Economic cycles, a wavelength between crests of development maxima over stagnation minima, are an active area of inquiry, not without controversy [13]. Juglar defined this periodicity over three phases: prosperity, crisis, and subsequent liquidation, and suggested an "approximate length of the cycle with crisis/liquidation taking 1-2 years, followed by a 6-7 years phase of prosperity [14, p. 7]," with drivers to prosperity to crisis transition due to exuberance and thus over-speculation (ibid.). Kitchin derived 'minor' and 'major' inventory cycles with wavelengths of 3.5 years (40 months) and "aggregates usually of two, and less seldom of three, minor cycles," respectively $[15$, p. 10]. Subsequent to the introduction of these short and intermediate cycles, Kondratieff introduced the concept of the long-wave
50-60 years cycles [16]. Concomitantly, Kuznetz extrapolated 15-25 years cycles derived from data from "fluctuations in rates of population growth and immigrating but, also with investment delays in building, construction, transport infrastructure, etc... [17, p. 2]." These authors extrapolated the information from a broad assortment of macro-economic data from US and Europe including climate, monetary, fiscal, consumption, among others.

Memory characteristics (also termed persistency) in the dynamics of typical econometrics captured over time are intimately connected with cycles and thus also to the underlying processes [18]. Technically, however, these same characteristics such as long-range memory processes are challenging to analyze and interpret due to (in part) selfsimilarity and typical non-stationary properties (as they confound spurious from true signals) [19]. The Hurst constant and wavelet analyses are statistical time series tools that may be calculated in such as a way as to avoid these challenges [20]. While there are other ways to define a Hurst constant, a measurement of memory, it is classically defined as $H \sim \ln (R / S)_{t} / \ln (t)$, where $R$ and $S$ is the rescaled range and standard deviation, respectively, and $t$ is a time window. An $H=0.5$, an $H<0.5$, and an $H>0.5$ indicates a random walk, an anti-persistent, and a persistent (trend reinforcing) time series, respectively [21]. Wavelet analyses is a wellestablished group of time series methods that leverages the expansion and contraction of wave functions to resolve time series properties [22].

In this work, and the to the author's knowledge, this is the first investigation of the existence and evolution of persistency, and the existence of approval cycles (akin to economic cycles) within US drug approvals, which is treated as a macro-economic variable and a proxy metric for FDA policy. This work is exploratory and empirical in nature. As presented in the Materials and Methods section below, the data source is a time series of monthly values of US drug Approvals from Jan. 1939 through Dec. 2019 from the Centers of Drug Evaluation and Research (CDER) branch of the Food and Drug Administration (FDA), which "regulates over-the-counter and prescription drugs, including biological therapeutics and generic drugs. "While this is not the only institution that regulates the DDD process within the FDA, it is one that provides a publicly, reliable and valuable source of longitudinal metrics regarding the DDD process from the dawn of the review process (1939) to the present time. The methods are standard with the exception of the Chronological Hurst Exponent to explore the persistency latent in the time series. All datasets and R Project code are provided in the Electronic Supplementary Materials section for the sake

\footnotetext{
$\overline{1}$ https://www.fda.gov/about-fda/fda-organization/center-drug-evalu ation-and-research-cder.
} 
of transparency and replicability as well as to encourage future researchers in investigate a potentially very interesting and informative aspect of drug development. This work then discusses the key results of both the descriptive and inferential statistics followed by a discussion on how the statistical work positively supports the hypotheses mentioned above (viz., persistency and economic cycles are latent within US drug approvals), and the ramifications of this work including potential linkages to sociological, economic, and policy features experienced over the nearly 100 years of data.

\section{Materials and Methodologies}

The following summarizes the data sources and the statistical approaches used. This work is applied by nature and thus differing the mathematical formulae and technical discussion to original sources, as cited. All data and the R Project code for the statistical analysis are provided in the Electronic Supplementary Materials section supporting this article for transparency and reproducibility, as well as for purposes of future work.

\section{Data Sources and Data Preparation}

The data were obtained from the FDA repository accessed at https://www.accessdata.fda.gov/scripts/cder/daf/ on July 16 and July 17, 2020. The data were culled from a monthly report and described as follows:

All Approvals and Tentative Approvals by Month. Reports include only BLAs/NDAs/ANDAs ${ }^{2}$ or supplements to those applications approved by the Center for Drug Evaluation and Research (CDER) and tentative NDA/ANDA approvals in CDER. The reports do not include applications or supplements approved by the Center for Biologics Evaluation and Research (CBER). Approvals of New Drug Applications (NDAs), Biologics License Applications (BLAs), and Abbreviated New Drug Applications (ANDAs), and supplements to those applications; and tentative approvals of ANDAs and NDAs.

Upon entry into the data-repository via the website, the number of approvals from January 1939 to December 2019 was then determined by month. The values were placed in Excel and then exported as a comma delimited comma-separated values (CSV) file for input into the data analysis routine.

The total dataset comprised 181,157 total approvals from January 1939 until December 2019 (for a total of 972

\footnotetext{
2 BLAs/NDAs/ANDAs: Biologics License Applications, New Drug Applications, Abbreviated New Drug Applications.
}

monthly observations). The author notes that submission history for each approval during this roughly 100-year time period was not found on the US FDA website.

\section{Statistical Analysis}

As mentioned above, as this is an applied paper, reference is made to the various theoretical formulae in the respective supportive citations. Many of the distribution-inquiring statistical tests selected are considered 'standard' in the sense that they are typically used in the context described and are readily available and interpretable. All methods presented below followed standard implementation; default parameters were used (as appropriate) throughout the analyses. While the $\mathrm{R}$ code [23] is presented in the Electronic Supplemental Materials section of this article, the steps to perform the analysis were as follows:

I. Load US Approvals as a time series and perform descriptive statistics (including autocorrelation functions) [24; R package: 'moments'].

In this step, the data are read as a time series into the $\mathrm{R}$ program, and descriptive statistics including moments and serial and partial correlation functions calculated.

II. Assess attributes of the time series, including:

o Normality [25; R package: 'nortest'] using the Anderson-Darling and Cramer-von Mises normality tests

o Stationarity [26; R package: 'aTSA'] using the Kwiatkowski-Phillips-Schmidt-Shin (KPSS) Unit Root Test for both the original and single difference

o Long-memory [27; R package: 'LongMemoryTS'] using the Qu and local Whittle score tests

o Seasonality [28; R package: 'seastests'] using the WO, QS, Friedman and Welch tests

o Nonlinearity [29; R package: 'nonlinearTseries'] using the Teraesvirta's and neural network tests, and Keenan, McLeod-Li, Tsay, and likelihood ratio tests.

III. Determine the Chronological Hurst Exponent (that is, evaluate if the Hurst exponent over time evolves):

For a given time series, the Hurst constant [30; $R$ package: 'tsfeatures'] is a statistical indicator of the memory in a time series process (or processes). In this calculation, the time-varying nature of the $\mathrm{H}$ constant was investigated using time windows from the first datapoint (Jan. 1939) to the end of the window length, with 1-month increments. The algorithm to calculate the Chronological Hurst Exponent is as follows: 


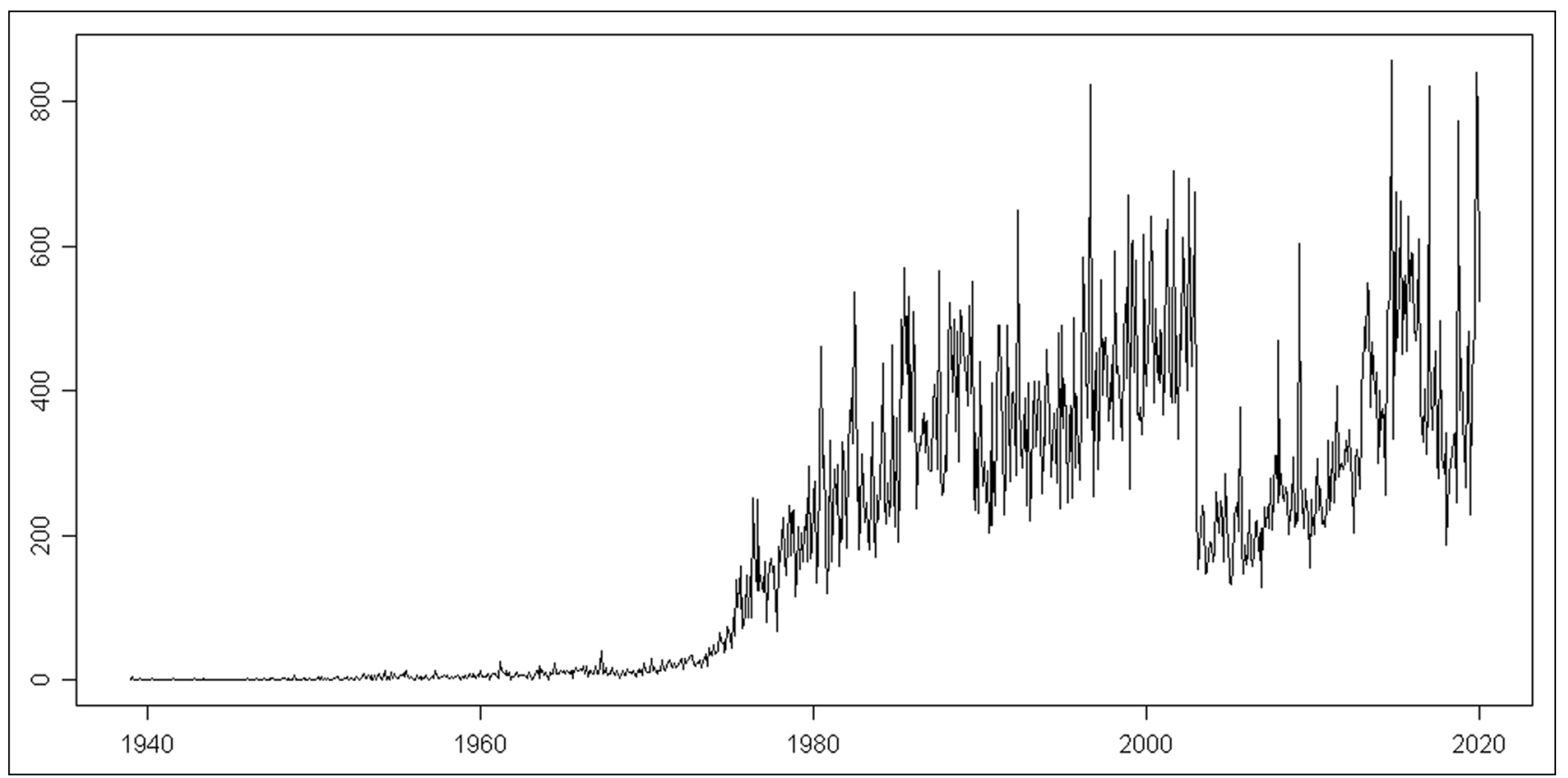

Figure 1 The Number of Monthly US CDER Approvals as a Function of Year from 1939 to 2019

Table 2 Descriptive Statistics of US Approvals (Rounded to Tenths; Units in Months)

\begin{tabular}{lcccccccc}
\hline Minimum & 1st Quartile & Median & Mean & Standard deviation & 3rd Quartile & Maximum & Kurtosis & Skew \\
\hline 0 & 5.0 & 164 & 186.4 & 190.9 & 392.2 & 858 & 2.6 & 0.7 \\
\hline
\end{tabular}

hurstApprovals $=0$; end $<-$ length(time)

for ( $i$ in 1:end) \{ hurstApprovals [i] <- hurst (time $\left.\left.\left[1:\left(1+\mathrm{i}^{*} 1\right)\right]\right)\right\}$

hurstApprovals<-ts(hurstApprovals, start=c $(1939,1)$, end $=c(2019,12)$, frequency $=12)$

IV. Determine the periodicities within the time series.

Wavelet analyses used to investigate the structure of the periodicities within the time series given its dynamics (particularly its non-stationarity; see step II). Two wavelet methods were utilized: one with a smoothing (Loess) approach [31; R package: 'WaveletComp'] and one [32-34; R Package: 'dplR'] without. The average period versus the average power for each method was then calculated to elucidate the main periodicities. The dominant frequency was then re-checked with spectral analysis [35, 36; R Package: 'forecast'].

\section{Results}

\section{Descriptive Statistics: Elementary Properties of the Chromodynamics of US Drug Approvals}

The time series of US drug approvals follows an interesting flow given the dramatic rise starting in the 1970s to 2000 then after a drastic fall with a subsequent re-rise (Fig. 1).

The US drug approvals time series distribution is nonnormal, platykurtic and positively skewed, with an average of 186 approvals (191 standard deviation) (Table 2 and $3)$. Importantly, the time series is non-stationary, nonseasonal, and non-linear, with intrinsic persistent memory (Table 2 and Fig. 2), which is removed with single differencing (that is, the time series has an order of integration (number of differences to attain stationarity) of $1, I(1)$ ). I(1) processes are rather well-represented across a spectrum of different disciplines and a broad assortment of the economic variables including US drug approvals [37]. 
Table 3 Summary of Tests Investigating Normality, Stationarity, Seasonality, Long-Memory, and Nonlinearity

\begin{tabular}{|c|c|c|c|}
\hline Test Category & Test Name & Test Statistic & Outcome Against Null Hypothesis \\
\hline \multirow[t]{2}{*}{ Normality } & Anderson-Darling test & $p$ value $<2.2 \mathrm{e}^{\wedge} 16$ & \multirow[t]{2}{*}{ Normal distribution rejected } \\
\hline & Cramer-von Mises test & $p$ value $<7.37 \mathrm{e}-10$ & \\
\hline Stationarity & KPSS unit root test ${ }^{\mathrm{a}}$ & $\begin{array}{l}0.01 \text { (for no drift/no trend; for drift/ } \\
\text { no trend; for drift/trend) }\end{array}$ & Stationarity rejected \\
\hline \multirow[t]{2}{*}{ Long memory } & Qu test ${ }^{\mathrm{a}}$ & $\begin{array}{l}1.033545 \text { versus } 1.517 \\
\quad(\text { alpha }=0.01 ; \text { eps }=0.02)\end{array}$ & \multirow[t]{2}{*}{ Long memory accepted } \\
\hline & Multivariate local Whittle Score ${ }^{a}$ & $\begin{array}{l}1.668473 \text { versus } 1.517 \\
\quad(\text { alpha }=0.01)\end{array}$ & \\
\hline \multirow[t]{2}{*}{ Seasonality } & Webel-Ollech test & \multirow[t]{2}{*}{$p$ value 0.05} & $\begin{array}{l}\text { "The WO-test does not identify } \\
\text { seasonality" }\end{array}$ \\
\hline & QS test, Friedman, Welch tests & & False—seasonality rejected \\
\hline \multirow[t]{6}{*}{ Linearity } & Teraesvirta's neural network test & $p$ value $=0$ & Linearity in "mean" rejected \\
\hline & White neural network test & $p$ value $=0$ & Linearity in "mean" rejected \\
\hline & Keenan's one-degree test & $p$ value $=3.889 \mathrm{e}^{\wedge}-5$ & $\begin{array}{l}\text { The time series follows some AR } \\
\text { process rejected }\end{array}$ \\
\hline & McLeod-Li test & $p$ value $=0$ & $\begin{array}{l}\text { The time series follows some } \\
\text { ARIMA process rejected }\end{array}$ \\
\hline & Tsay’s test & $p$ value $=6.45 \mathrm{e}^{\wedge}-14$ & $\begin{array}{l}\text { Time series follows some AR } \\
\text { process rejected }\end{array}$ \\
\hline & $\begin{array}{l}\text { Likelihood ratio test for threshold } \\
\text { nonlinearity }\end{array}$ & $p$ value $=0.0004552571$ & $\begin{array}{l}\text { Time series follows some TAR } \\
\text { process rejected }\end{array}$ \\
\hline
\end{tabular}

${ }^{\text {a }}$ Some tests require stationary data. As such, as the number of differences required for a stationary series from the original time series was 1 , the difference was used in the specific test demarcated

\section{Chronological Hurst Exponent: Existence of Economic Cycles and Latent Persistency}

Using the Chronological Hurst Exponent approach to investigate the long-term memory processes of the time series shows, interestingly, a unique trichotomized structure (Fig. 3). Three periods are clearly shown: Period 1: prior to June 1947, a period of stagnation with $H \sim 0.5$; Period 2: June 1947 to May 1974 , a period of time-varying nature (also herein called emergent), where the $\mathrm{H}$ constant fluctuates rises under a degree of fluctuation; and, Period 3: May 1974 to Dec 2019, a period of saturation in which the $H \sim 1$.

Concordantly, the wavelet periodogram during Period 3 demonstrates that the time series contains periodicities. Several relatively long-, medium-, and short-range periodicities are observed during this period: 16-18 years (with a maximum (black ridge) occurring at 17 years), 4-8 years, and on the monthly, yearly, or biyearly periodicities presenting intermittently, respectively (Fig. 4). The predominate periodicity is identified to be 17,8 and 4 years from spectral analysis (Fig. 5).

\section{Discussion and Conclusion}

Using time series analysis, this work finds two conceptually novel aspects of US drug approvals: the existence and evolution of persistency, and the existence of approval cycles (akin to economic cycles).

\section{Persistency}

Formally, persistency may be defined as the "rate at which its autocorrelation function decays to zero," or "the extent to which events today have an effect on the whole future history of a stochastic process [38]." Translating to the context of our concern, it generally means that the value of US drug approvals at a given month is closely related to its value at the prior month. The Chronological Hurst Exponent proposed herein is a simple algorithm that reiteratively calculates the Hurst exponent (a measure of persistency) over an incrementally increased time period. With each iteration, an additional data point (here the next monthly observation of US approvals) is taken into account until the exponent of the 

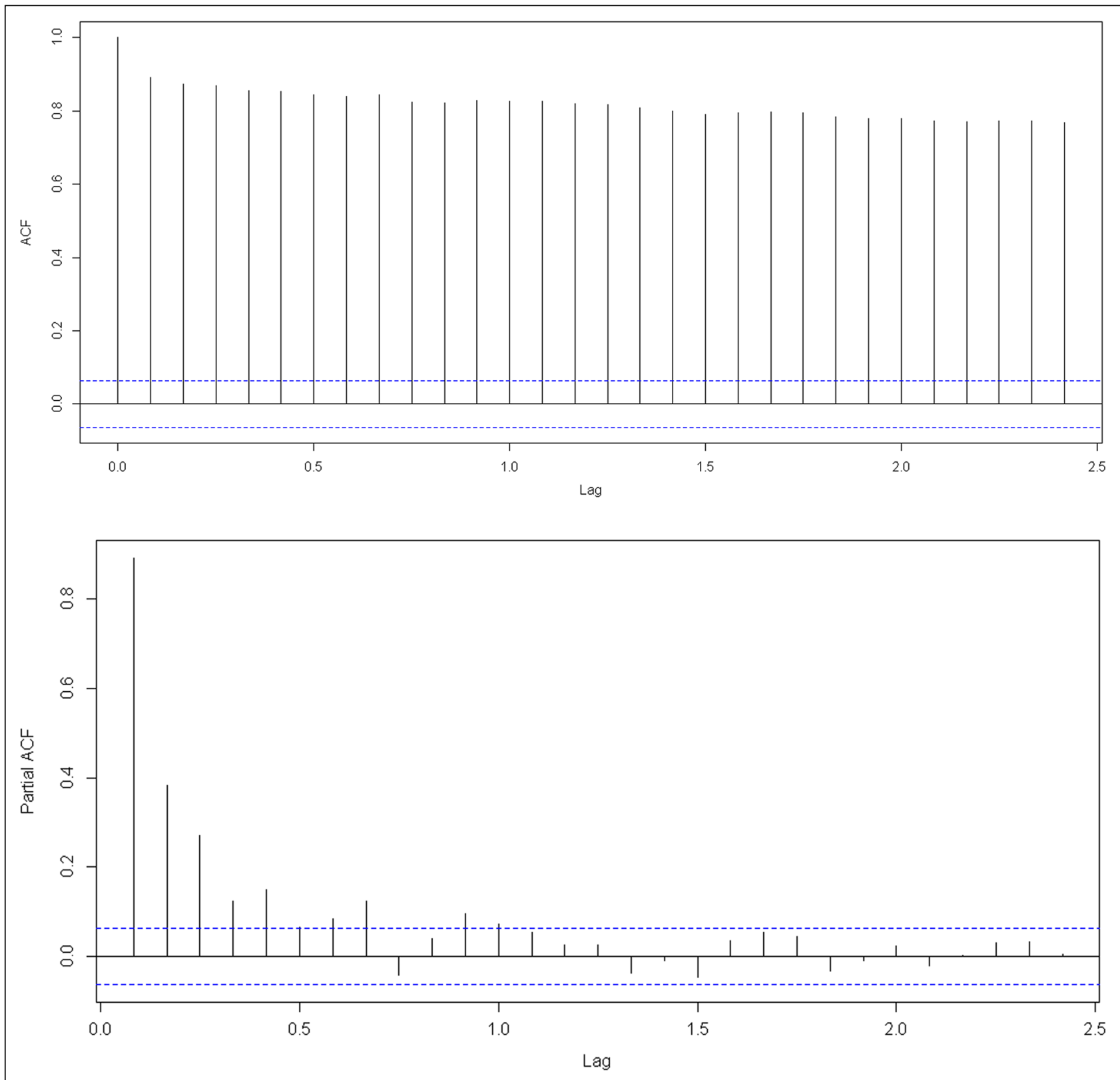

Figure 2 Serial and Partial Correlation Functions: Lag is Presented in Months

full data set is calculated. The Chronological Hurst Exponent proposed in this work elucidated a S-shaped structure reflecting a trichotomized picture of the time evolution of persistency latent within US drug approvals:

- Period 1: An 8-year (1939-1947) stagnation period in which the Hurst exponent remained at or around 0.5. An Hurst exponent at these values suggest no persistency whatsoever.
- Period 2: A 27-year (1947-1974) time-varying (emergent) period in which the Hurst exponent gradually evolved from 0.5 to 0.9 . This range in the Hurst exponent suggests a growing persistency within the time series data.

- Period 3: A 45-year (1974-2019) saturation period in which the Hurst exponent remained at or around 1. A saturated Hurst exponent implies that the time series has become (for lack of a better term) inelastic; that is, any further changes in the degree and/or number of exogenous variables do not affect the persistency course of the time series (as it is already maximized). 


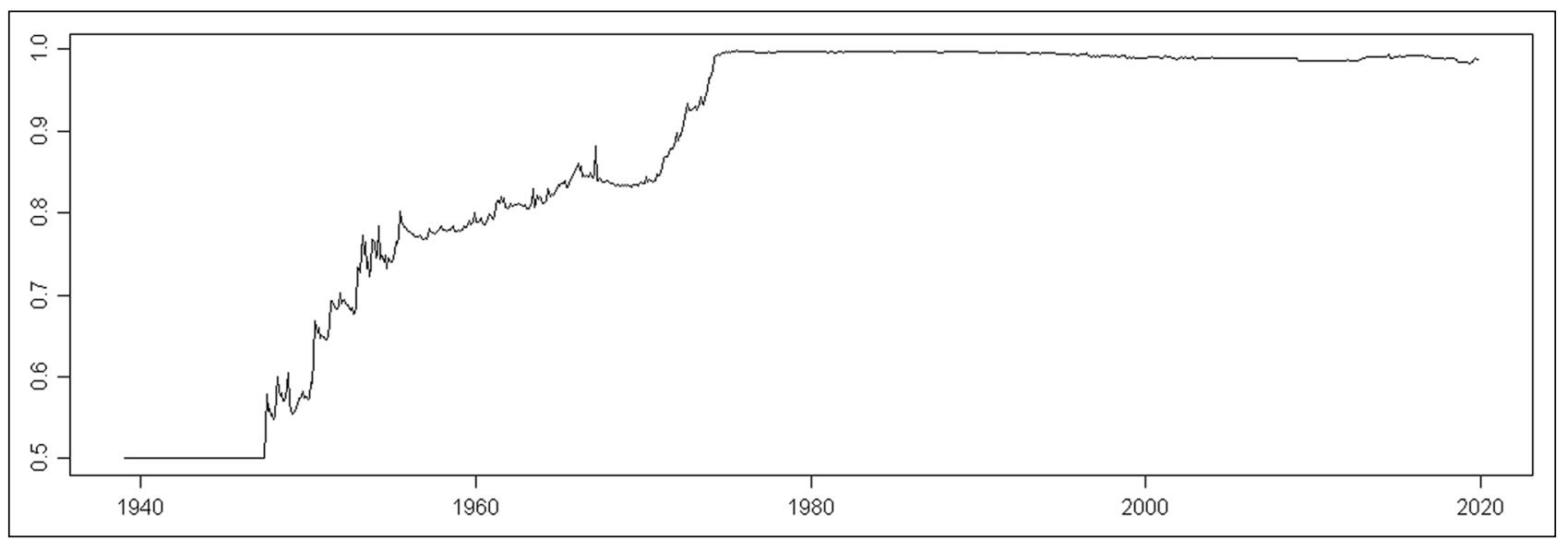

Figure 3 The Chronological Hurst Exponent Based on US Drug Approvals (Fig. 1) from 1939 to 2019

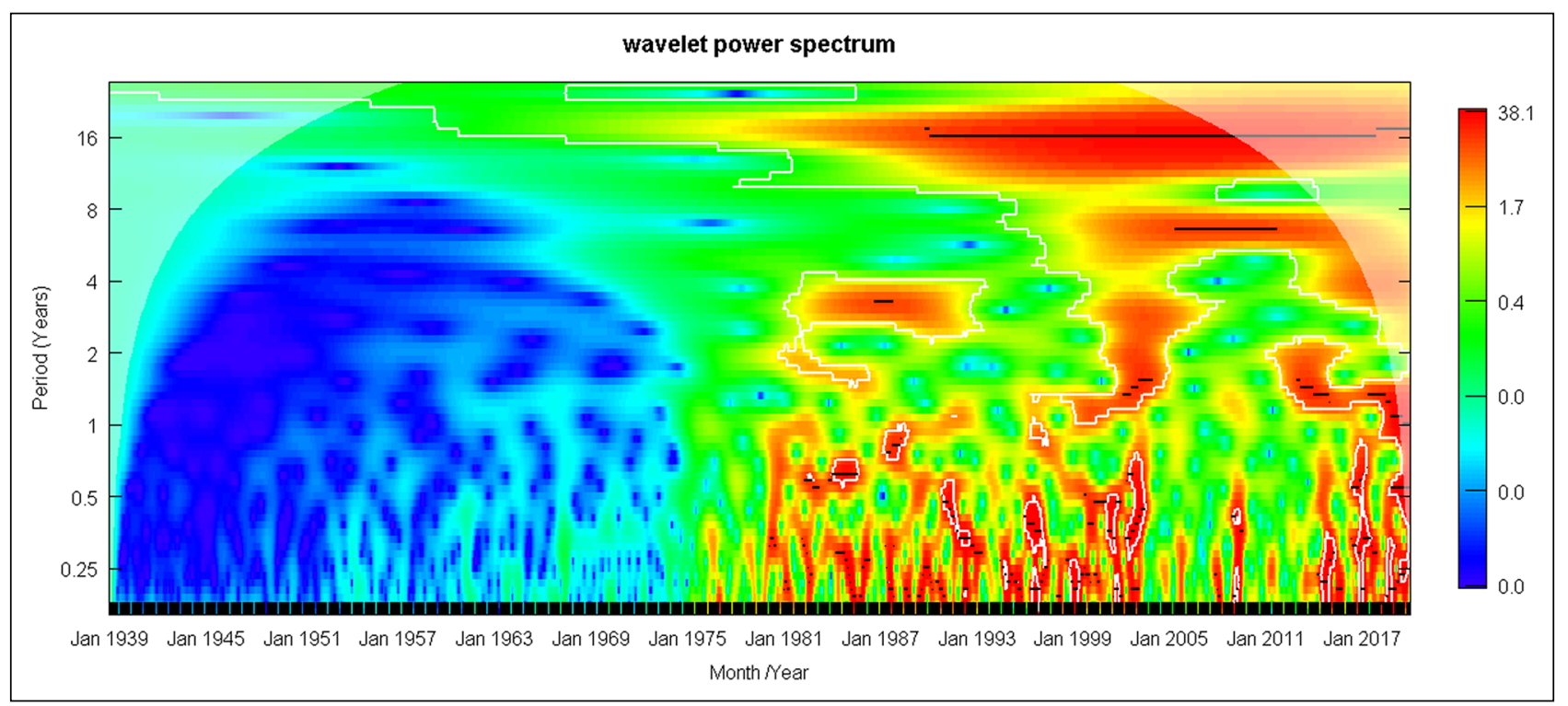

Figure 4 Wavelet Periodogram of US Approvals: Black Lines are the Wavelet Power Ridges and White Contour Lines to Border the Area of Wavelet Power Significance of $99 \%$

\section{Cyclicity}

Interpreting US drug approvals as an economic variablea singular outcome of several complex macro- (national), meso- (cluster), and micro (firm)-inputs such as national policy and R\&D spend (government, firm), potential of future rents (individual buyer, payor), science and technology innovation (tacit (e.g., staff dexterity) and explicit (e.g., patents) knowledge), and resource availability (e.g., chemicals, vials) - the existence of business cycles were investigated. Several tiered periodicities (17 years, 4-8 years, and intermittent monthly/yearly) were identified within Periods 2 and 3 of the CHE. Thus, one of the key findings of this work is that approval cycles, similar to economic cycles, exist. These approval cycles seem to be the result of explanatory variables that are working in a cumulative manner.

\section{Persistence and Cyclicity Interpreted}

During Period 2 [27-years (1947-1974)], it is observed that 1947 was the first year in which there were one or more approvals during much of the year and had the largest number on an annual basis since the start of the collection cycle in Jan 1939. After 1947, a general rise in the number of approvals per month and per annum is observed. It is also a period of commensurate changes to the policy and social landscape pertaining to DDD, as well as continued investment into R\&D. These changes were seemingly due to end of World War II (1939-1945), the beginning of the so-called 


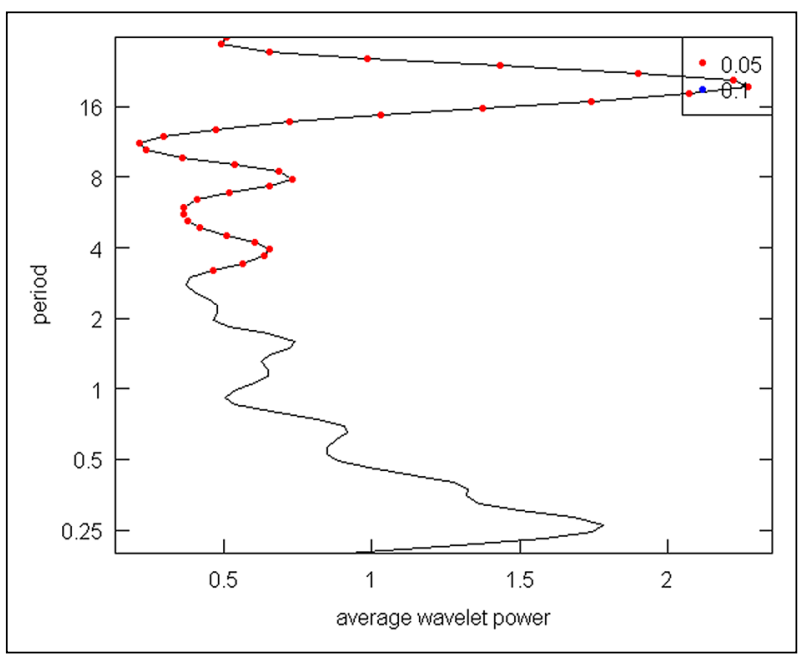

Figure 5 Wavelet period versus power with 95\% significant levels in red

'Golden Age of Capitalism,' and the associated economic progress [39] with a relatively small number of economic disasters (see Fig. 3 in [40]). Since the 1938 Food, Drug and Cosmetic act, no significant advances in policy occurred until the 1962 Drug Amendments (see Table 1), while there were significant milestone activities in terms of congressional review (the Kefauver Hearings dealt with pricing and market control [41]. One could therefore speculate that it an overall increased economic activity (and not specific FDA policy changes, per se) that may have driven the changes in the persistency measurement.

The appearance of Period 3 [45-years (1974-2019)] suggests a uniform pressure onto the time series. Two general reasons present themselves to foment such a sustained persistent alteration in the fabric of US drug approvals: some sort of substantive and everlasting change (1) to accounting practices regarding US drug approvals (that is, how the source data were initially contrived and/or collected); or (2) in the scientific, social, economic, and/or legislative landscape. The former is unlikely to cause a persistent shift. To illustrate, FDA data sources state a change in department ownership in and around that time, as well as issues regarding changes from fiscal to calendar year practices. ${ }^{3}$ It is unlikely that either of these reasons would have changed the time series in such a permanent manner. The latter reason, while likely, however, is ill-defined, but does allow for hypothesis generation.

One hypothesis that could be tested is that of a significant change in the FDA policy landscape (see Table 1) may have

\footnotetext{
${ }^{3}$ Data record information from https://www.fda.gov/about-fda/histo ries-product-regulation/summary-nda-approvals-receipts-1938-prese nt (extracted on July 30, 2020).
}

Table 4 Mapping of Broad Canonical Economic Cycles with that of Periodicities Associated with US Approvals

\begin{tabular}{lll}
\hline \multicolumn{1}{c}{ Theory } & \multicolumn{1}{c}{$\begin{array}{c}\text { Perio- } \\
\text { dicity } \\
\text { (Years) }\end{array}$} & \multicolumn{1}{c}{ US Approvals } \\
\hline Kitchin short-term cycle & 3.5 & Months to biannual \\
Juglar mid-term cycle & $7-11$ & $4-8$ years \\
Kuznets medium-term cycle & $15-25$ & 17 years \\
Kondratieff long-term cycle & $40-60$ & \\
\hline
\end{tabular}

caused the formation of Period 3. From an FDA perspective, the 1960s and 1970s were a transformative vicennial [10]. In 1962, the Kefauver-Harris (KH) amendments to the original Food, Drug and Cosmetics Act (FD\&C) of 1938 introduced (inter alia) broad requirements on drug efficacy (including key concepts of 'substantial evidence' and 'adequate and well-controlled studies'), drug quality (via good manufacturing practices), ethical guidelines (patient informed consent), and physician-researcher supervision of the clinical trials. Subsequently, a review of prior-to-1962 approved drugs were retrospectively investigated based on the evidentiary standard of the $\mathrm{KH}$ amendments, which led to revocation of "over 1000 ineffective drugs and drug combinations from the marketplace (page 13 of ibid.)." The concepts such as those introduced in the $\mathrm{KH}$ amendments (partly listed above) have been refined and reinforced through ongoing congressional action, directly contributing to the identified persistency affect and cyclicity. Ongoing policy actions, such as Prescription Drug User Fee Act (PDUFA) and its subsequent 5-year amendments commencing in 1992, or the introduction of new technologies may have directly contributed to innovation-based periodicities, leading to significant increases in the promulgation of guidelines that may have furthered drug approvals [37, 42].

Thinking outside of the drug development process and continuing considering the periodogram (Fig. 5) and thinking of the original time series (Fig. 2), the complex periodicity profile may have been motivated by socio-economic factors. Substantive economic pulses that may have affected the overall approval flow may include: Black Monday Market Crash (October 19, 1987), the Dot-Com bubble burst (Q3, 2002), and the subprime mortgage crisis (September 17, 2008), among others. Visually, the Dot-Com bubble burst seemed to coincide with a downsizing of amplitude. However, it is difficult to ascertain if the other triggers may have affected the time series.

Interestingly, if one considered the US drug approvals strictly as an economic variable, and assuming the theory of Schumpeter's economic cycles, the identified periodicities seem to coincide with certain macro-economic periodicities, with exception as no canonical long-term ( $>40$ years) periodicities were identified in this analysis (see Table 4). The 
periodicities began at different times with different durations (Fig. 4). The dominant periodicity of 17,8 and 4 years has reoccurred during the longest (45 years), medium (20 years), and short-term (intermittent) durations, respectively (Fig. 5). Thus, it seems that US drug approvals follow a Juglar/ Kuznets mid-term cycle with Kitchin bursts. Only time will tell if a longer-term cycle (Kondratieff) emerges, irrespective of any downside pressures (such as multi-decade bear cycles). A key difference between the identified approval cycles as compared with economic cycles may be the degree of importance of the regulatory context. While a potentially coarse interpretation, without the legal requirement for market approval there would not have been a US drug approvals time series, whereas for variables such as gross domestic product typically used to consider economic cycles this is not the case (as the legal regimes do not define (as much as support) the existence of these more traditional economic variables).

\section{Further Thoughts in Light of Limitations of Current Study}

There are extensions and limitations to any statistical analyses, especially when dealing with social-economic variables. Examples of future investigation may include.

\section{Hypothesis}

- One could argue that the number of US drug applications may have been a more insightful variable, as applications may be either withdrawn (by the Sponsor) or rejected (by the FDA). Unfortunately, the author could not find this dataset.

- The number of initial US drug applications or approvals for new molecular and/or biologic entities may provide additional insight into the economics of the innovative process. In this article, the total number of US drug approvals including generics and line extensions (e.g., new indications or dosage forms) were considered, as reflected "market innovation." That is, a sponsor would not have considered seeking an approval without a market driver of some sort.

\section{Data}

- Data integrity and completeness: This study relies on a single source dataset from the FDA. While the author feels comfortable with the data source, there is uncertainty in how the data are collected, maintained, and presented given the duration of data collection and limitedto-no ability to cross-reference.

- Data transformation: The data were transformed from irregular to a regular time structure. That is, FDA drug approvals occurred as a function of day; these data were then aggregated into monthly values to facilitate the statistical analyses. Thus, some information may have been lost in terms of structure, as there are limited statistical routines able to manage such data.

In the author's opinion, these data are an important artifact of R\&D expenditures related to the DDD industry and therefore have interesting utility. Future investigations may consider these data and analyses to support research questions such as those related to forecasting and long-memory effects of non-stationary and non-linear data. It will be interesting to revisit these analyses on a yearly basis given the recent COVID-19 crises and resultant economic challenges, with a hope that the US drug approvals remain persistent with respect to these significant triggers.

\section{Study Conclusions}

In conclusion, this work introduces the Chronological Hurst Exponent, an algorithm which examines the time evolution of long-term memory intrinsic to time series data. Using this algorithm, US drug approvals are examined. The CHE of US drug approvals is found to follow a distinctive S-shaped (trichotomized) curve, with three periodicities that seem to be correlative with the evolving US drug development policy landscape, as well as macro-variable changes that may be relevant to drug development. Further, using wavelet analysis, cyclicity in the frequency of US drug approvals was observed in the most recent period identified in the CHE analysis. These periodicities adds evidence to the concept of mid-term economic cycles, assuming US drug approvals data are viewed a proxy metric of innovative capacity. The empirical findings and statistical approaches outlined in this report promise an exciting new frontier of further research into the various forces driving drug development.

\section{Acknowledgements}

The author extends gratitude N.D., S.L.D., and N.L.D. for their support of the manuscript.

\section{Declarations}

\section{Disclosures}

The author is an employee of Takeda Pharmaceuticals; however, this work was completed independently of his employment. The views expressed in this article may not represent those of Takeda Pharmaceuticals. As an Associate Editor for Therapeutic Innovation and Regulatory Science, the author was not involved in the review or decision process for this article. See Electronic Supplementary Materials for all data and methods to replicate (or extend) the results presented herein. 


\section{Supplementary Information}

The online version contains supplementary material available at https:// doi.org/10.1007/s43441-021-00279-8.

\section{References}

1. Daizadeh I, Miller D, Glowalla A, et al. A general approach for determining when to patent, publish, or protect information as a trade secret. Nat Biotechnol. 2002;20:1053-4. https://doi.org/10. 1038/nbt1002-1053.

2. Wouters OJ, McKee M, Luyten J. Estimated research and development investment needed to bring a new medicine to market, 2009-2018. JAMA. 2020;323(9):844-53. https://doi.org/10.1001/ jama.2020.1166.

3. DiMasi JA, Grabowski HG. R\&D costs and returns to new drug development: a review of the evidence. In: Danzon PM, Nicholson $\mathrm{S}$, editors. The Oxford handbook of the economics of the biopharmaceutical industry. Oxford: Oxford University Press; 2012.

4. Munos B. Lessons from 60 years of pharmaceutical innovation. Nat Rev Drug Discov. 2009;8:959-68. https://doi.org/10.1038/ nrd2961.

5. Parida D, Mehdiratta R, Saberwal G. How many patents does a biopharmaceutical company need? Nat Biotechnol. 2008;26:7636. https://doi.org/10.1038/nbt0708-763.

6. Agarwal P, Searls D. Can literature analysis identify innovation drivers in drug discovery? Nat Rev Drug Discov. 2009;8:865-78. https://doi.org/10.1038/nrd2973.

7. D'Alise C, Giustiniano L, Peruffo E. Innovating through clusters. Int J Eng Bus Manag. 2014. https://doi.org/10.5772/59028.

8. Daizadeh I. An intellectual property-based corporate strategy: an R\&D spend, patent, trademark, media communication, and market price innovation agenda. Scientometrics. 2009;80:731-46. https:// doi.org/10.1007/s11192-008-2105-9.

9. Daizadeh I. Issued US patents, patent-related global academic and media publications, and the US market indices are inter-correlated, with varying growth patterns. Scientometrics. 2007;73:29 36. https://doi.org/10.1007/s11192-007-1749-1.

10. Junod SW. FDA and clinical drug trials: a short history. In Davies M, Kerimani F, editors. A quick guide to clinical trials. Washington: Bioplan, Inc.; 2020, 2008, p. 25-55. Viewed on July 30 from the FDA website: https://www.fda.gov/media/110437/download.

11. Chorniy A, Bailey J, Civan A, Maloney M. Regulatory review time and pharmaceutical research and development. Health Econ. 2021;30:113-28. https://doi.org/10.1002/hec.4180.

12. DiMasi JA, Wilkinson M. The financial benefits of faster development times: integrated formulation development, real-time manufacturing, and clinical testing. Ther Innov Regul Sci. 2020;54:1453-60. https://doi.org/10.1007/s43441-020-00172-w.

13. Kozlowski D. Old series, new signals: the economic cycle in light of wavelet analysis. Cuadernos Del CIMBAGE 2019;2(21). https://ojs.econ.uba.ar/index.php/CIMBAGE/article/view/1587

14. Besomi D. Clément Juglar and the transition from crises to business cycle theories. Paper prepared for a conference on the occasion of the centenary of the death of Clément Juglar, Paris, 2 December 2005. https://www.unil.ch/files/live/sites/cwp/files/ users/neyguesi/public/D.Besomi_http://citeseerx.ist.psu.edu/ viewdoc/download?doi=10.1.1.693.7740\&rep=rep1\&type=pdf.

15. Kitchin J. Cycles and trends in economic factors. Rev Econ Stat. 1932;5(1):10-6.

16. Kondratieff ND, Stolper WF. The long waves of economic life. Rev Econ Stat. 1935;17(6):105-15.
17. Kwasnicki W. Date Unknown. Kitchin, Juglar and Kuznetz business cycles revisited. http://kwasnicki.prawo.uni.wroc.pl/todow nload/Kwasnicki_cyclesJEBO.pdf. Accepted 08 June 2020.

18. Alvarez-Ramirez J, Rodriguez E, Ibarra-Valdez C. Mediumterm cycles in the dynamics of the Dow Jones Index for the period 1985-2019. Phys A. 2020;546:124017. https://doi.org/ 10.1016/j.physa.2019.124017.

19. Saha K, Madhavan V, Chandrashekhar G. Pitfalls in long memory research. Cogent Econ Finance. 2020;8(1):1733280. https:// doi.org/10.1080/23322039.2020.1733280.

20. Chamoli A, Bansal AR, Dimri VP. Wavelet and rescaled range approach for the Hurst coefficient for short and long time series. Comput Geosci. 2007;33(1):83-93. https://doi.org/10.1016/j. cageo.2006.05.008.

21. Mandelbrot BB, Wallis JR. Noah, Joseph, and Operational Hydrology. Water Resour Res. 1968;4(5):909-18. https://doi. org/10.1029/WR004i005p00909.

22. Walnut DF. An introduction to wavelet analysis. Boston: Birkhäuser; 2013.

23. R Core Team. R: A language and environment for statistical computing. Vienna: R Foundation for Statistical Computing; 2020. https://www.R-project.org/.

24. Komsta L, Novomestky F. moments: Moments, cumulants, skewness, kurtosis and related tests. R package version 0.14 ; 2015. https://CRAN.R-project.org/package=moments.

25. Gross J, Ligges U. nortest: Tests for Normality. R package version 1.0-4; 2015. https://CRAN.R-project.org/package=nortest.

26. Qiu D. aTSA: Alternative Time Series Analysis. R package version 3.1.2; 2015. https://CRAN.R-project.org/package=aTSA.

27. Leschinski C. LongMemoryTS: Long Memory Time Series. R package version 0.1.0; 2019. https://CRAN.R-project.org/packa ge $=$ LongMemoryTS.

28. Ollech D. seastests: Seasonality Tests. R package version 0.14.2; 2019. https://CRAN.R-project.org/package=seastests.

29. Garcia CA. nonlinearTseries: Nonlinear Time Series Analysis. R package version $0.2 .10 ; 2020$. https://CRAN.R-project.org/ package $=$ nonlinearTseries.

30. Hyndman R, Kang Y, Montero-Manso P, Talagala T, Wang E, Yang Y. O'Hara-Wild M. tsfeatures: Time Series Feature Extraction. R package version $1.0 .2 ; 2020$. https://CRAN.Rproject.org $/$ package $=$ tsfeatures.

31. Roesch A, Schmidbauer H. WaveletComp: Computational Wavelet Analysis. R package version 1.1; 2018. https:// CRAN.R-project.org/package=WaveletComp.

32. Bunn AG. A dendrochronology program library in R (dplR). Dendrochronologia. 2008;26(2):115-24. https://doi.org/10. 1016/j.dendro.2008.01.002.

33. Bunn AG. Statistical and visual cross-dating in $\mathrm{R}$ using the dplR library. Dendrochronologia. 2010;28(4):251-8. https://doi.org/ 10.1016/j.dendro.2009.12.001.

34. Bunn A, Korpela M, Biondi F, Campelo F, Mérian P, Qeadan F, Zang C. dplR: Dendrochronology Program Library in R. R package version: 1.7.1; 2020. https://CRAN.R-project.org/packa ge $=$ dplR.

35. Hyndman R, Athanasopoulos G, Bergmeir C, Caceres G, Chhay L, O'Hara-Wild M, Petropoulos F, Razbash S, Wang E, Yasmeen F. forecast: Forecasting functions for time series and linear models. R package version 8.12; 2020. http://pkg.robjh yndman.com/forecast.

36. Hyndman RJ, Khandakar Y. Automatic time series forecasting: the forecast package for R. J Stat Softw. 2008;26(3):1-22.

37. Daizadeh I. Investigating Rates of Food and Drug Administration approvals and guidances in drug development: a structural breakpoint/cointegration timeseries analysis. Ther Innov Regul Sci. 2020;54(5):1056-67. https://doi.org/10.1007/ s43441-020-00123-5. 
38. Caporale GM, Pittis N. Persistence in macroeconomic time series: is it a model invariant property? Rev Econ Rosario. 2001;4(2):117-42.

39. Zakamulin V, Hunnes JA. Stock earnings and bond yields in the US 1871-2017: the story of a changing relationship. Q Rev Econ Finance. 2020. https://doi.org/10.1016/j.qref.2020.05.013.

40. Coric B. Economic disasters: a new data set. Financ Res Lett. 2020. https://doi.org/10.1016/j.frl.2020.101612.
41. Greene JA, Podolsky SH. Reform, regulation, and pharmaceuticals-the Kefauver-Harris Amendments at 50. N Engl J Med. 2012;367:1481-3. https://doi.org/10.1056/NEJMp1210007.

42. Daizadeh I. Since the mid-2010s FDA drug and biologic guidelines have been growing at a faster clip than prior years: is it time to analyze their effectiveness? Ther Innov Regul Sci. 2020. https:// doi.org/10.1007/s43441-020-00233-0. 